\title{
A STATISTICAL STUDY OF NOCTURNAL ENURESIS
}

\author{
BY \\ ROBINA S. ADDIS.
}

Bed-wetting is a common and troublesome problem which faces many who have the care of children. No cure seems specific and there are many theories current as to its causation and consequently the treatment required. Accordingly it should be profitable to enquire more exactly into the symptom. It seems the time to abandon mere generalizations and to present actual figures. This study is confined to simple factual data capable of statistical analysis and psychological findings (which it is hoped to publish elsewhere) have been omitted. At the end of 1933 the Child Guidance Council (founded in 1927) appointed a psychiatric social worker to carry out research on enuresis for one year. Material was obtained from the case records of six Child Guidance Clinics in London. The research work was under the direction of a committee consisting of Drs. Mildred Creak, R. D. Gillespie, Emanuel Miller and William Moodie. It was decided to go through a section of the records to pick out the enuretic children and then compare them with the remaining non-enuretics in different ways. The year 1932 was chosen (the last completed year before the research began) and all the 1,705 new cases which attended during that year at the six clinics were carefully studied. Bed-wetting is so much a routine question in Child Guidance Clinics that it was safe to assume that the symptom if present would be recorded and division into the two groups was valid. Not only those referred for bed-wetting but all who wet the bed were classed as enuretic. The cases had already been selected by the mere fact of having been referred to a clinic which is for difficult or nervous children, but this applies to both groups so that they can safely be compared with each other.

Full psychiatric clinic records have been kept for so few years that all the tables in which time is a factor (e.g. age, place in family) must be conditioned by this fact. It cannot be questioned why elder brothers and sisters or parents were not sent to the clinic, nor why the child himself did not come much earlier because the treatment simply was not available. All that can be said in this enquiry is that conditions are the same for the non-enuretics as for the enuretics, but one group may be affected more than the other. The future will bring the required knowledge and there is rapidly increasing material as the work of the clinics extends yearly.

Accordingly this work is perforce preliminary. The results offered are intended to stimulate interest in the problem and to suggest lines for further 
research. Intensive study of cases of enuresis provides such a net-work of possible factors that it is salutary to make an extensive survey submitted to the discipline of figures. The following results are founded on figures from the total new cases $(1,705)$ in 1932 at the six Child Guidance clinics. All figures are worked out to the first decimal place.

Incidence of enuresis.

Enuretics as a percentage of the total cases at each clinic give the following figures:-

\begin{tabular}{|c|c|c|c|c|c|c|c|}
\hline $\begin{array}{ll}\text { Clinics } \ldots . & \ldots \\
\text { Percentage } & \ldots\end{array}$ & I & II & III & IV & $\mathbf{V}$ & VI & Average \\
\hline of enuretics & $17 \cdot 1$ & $18 \cdot 7$ & $14 \cdot 4$ & $22 \cdot 5$ & 18.9 & $16 \cdot 8$ & $18 \cdot 4$ \\
\hline
\end{tabular}

These differences are not significant and may be accounted for by domestic reasons. At clinic IV some research was being undertaken in enuresis and the consequent inquiries may have led to other bed-wetting cases being referred, i.e. institutions and families finding the symptom considered of interest in one patient might bring up others for the same reason. Clinic III was in its first year and had fewer cases than the others so that its percentage is less reliable.

The total of 18.4 per cent. probably considerably under-estimates the incidence of enuresis among the general child population, since there are many other treatments (including the traditional chastisement) offered besides psychiatry.

\section{Sex incidence.}

1. Differences between the clinics.-The expected proportions between boys and girls if there were no sex differentiation in enuresis have been compared with the actual figures for enuretics and non-enuretics at the six clinics (see fig. 1). The results show that in clinics IV and VI there are

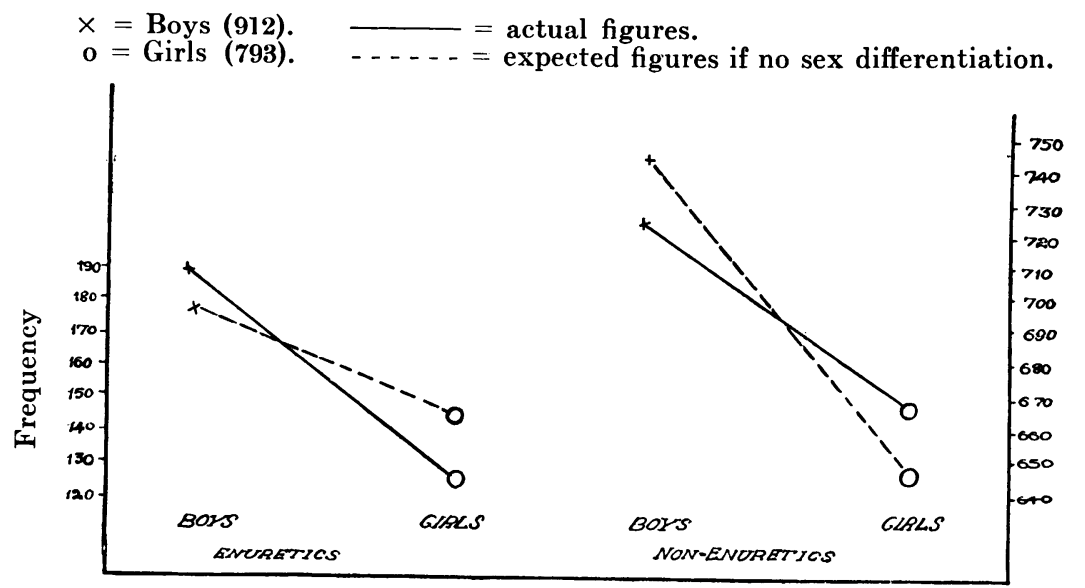

FIG. 1.

significantly more enuretics among the boys than among the girls. In the remaining four clinics the differences are not significant. (In III and V the excess is still among the boys but in I and II the proportion of the girls is slightly higher.) 
2. Combined clinics. - If all the clinics are combined the findings are as follows:-

\begin{tabular}{|c|c|c|c|c|c|c|}
\hline Enuretics & $\left\{\begin{array}{l}\text { actual figures } \\
\text { expected figures }\end{array}\right.$ & $\begin{array}{l}\cdots \\
\cdots\end{array}$ & $\begin{array}{l}\cdots \\
\cdots\end{array}$ & $\begin{array}{c}\text { Boys. } \\
189 \\
168\end{array}$ & $\begin{array}{c}\text { Girls. } \\
125 \\
146\end{array}$ & $\begin{array}{r}\text { Total. } \\
314\end{array}$ \\
\hline \multirow[t]{2}{*}{ Non-enuretics } & $\left\{\begin{array}{l}\text { actual figures } \\
\text { expected figures }\end{array}\right.$ & $\begin{array}{l}\cdots \\
\cdots\end{array}$ & $\begin{array}{l}\cdots \\
\cdots\end{array}$ & $\begin{array}{l}723 \\
744\end{array}$ & $\left.\begin{array}{l}668 \\
647\end{array}\right\}$ & 1,391 \\
\hline & & & & 912 & 793 & 1,705 \\
\hline
\end{tabular}

There are more boys than girls in the clinic population but even allowing for that there is a higher proportion of enuretics among the boys than would be expected if there were no connection with sex. Putting it to the nearest tenth of a number, it may be said that the proportions of boys and girls are as follows: enuretics $3: 2$ and non-enuretics $2 \cdot 2: 2$.

\section{Intelligence quotients.}

1. Differences between the clinics.-(a) Enuretics are not a sufficient number $($ total $=225$ ) to prove that the variation among the clinics about the mean (I.Q. 97) is more than a chance effect.

(b) Non-enuretics (total=982) show a difference which might be regarded as statistically significant, e.g. between the means I.Q. 90.4 and I.Q. 90.5 of clinics II and III and the mean I.Q. 100.8 of clinic V. (Probable reasons for this may be found in the different class of patient which each clinic tends to attract according to its locality and working conditions. Allowance must also be made for the personal factor in different workers giving the tests.) See fig. 2 and 3 , and table 1.

Intelligence quotients at the six clinics.
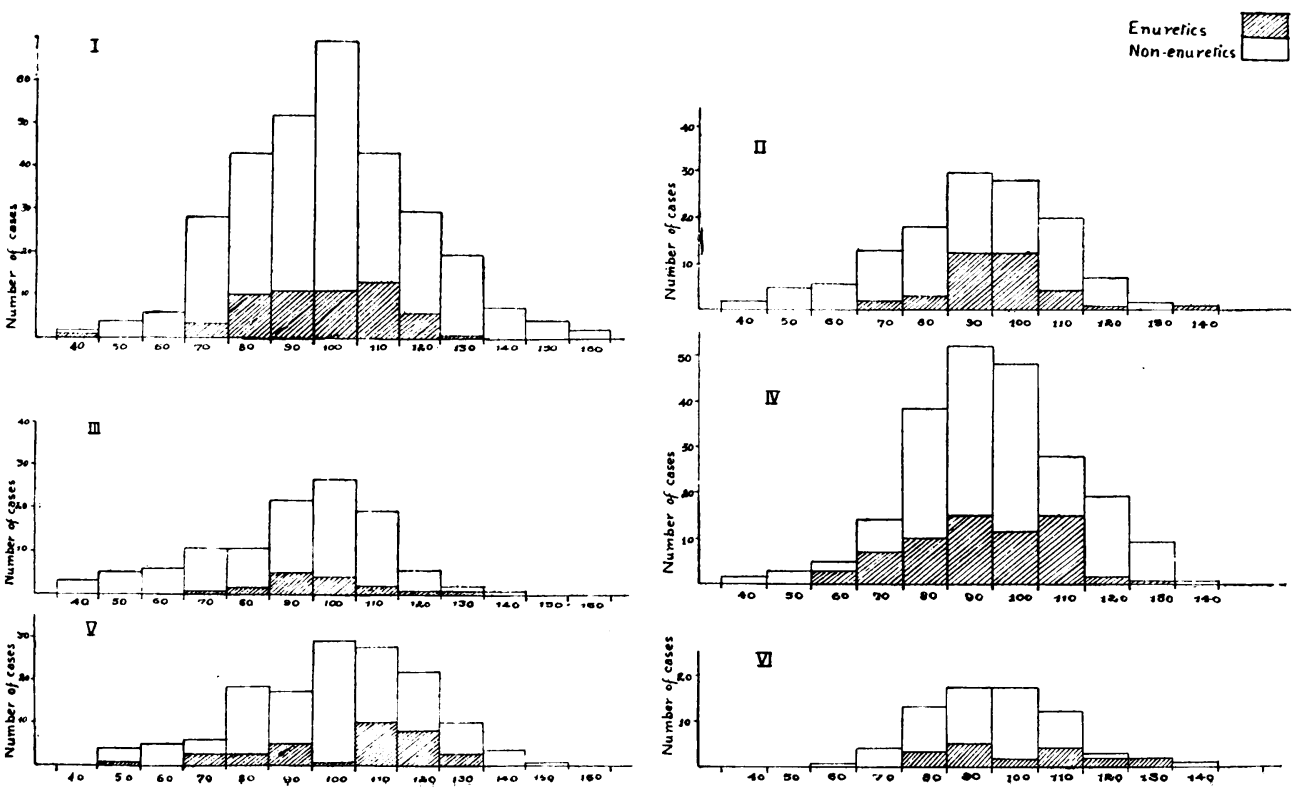

FIG. 2.

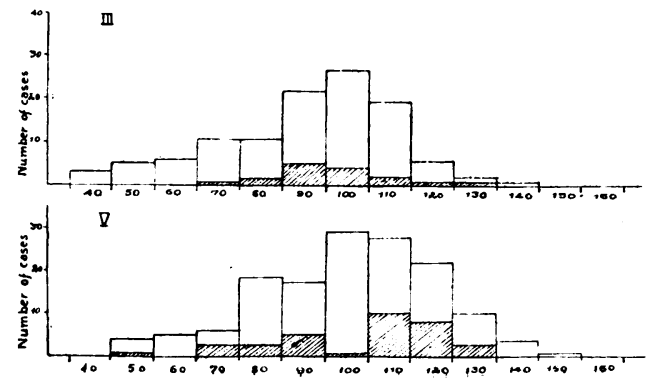


Chart shewing mean I.Q. for enuretic and non-enuretic children at six clinics.

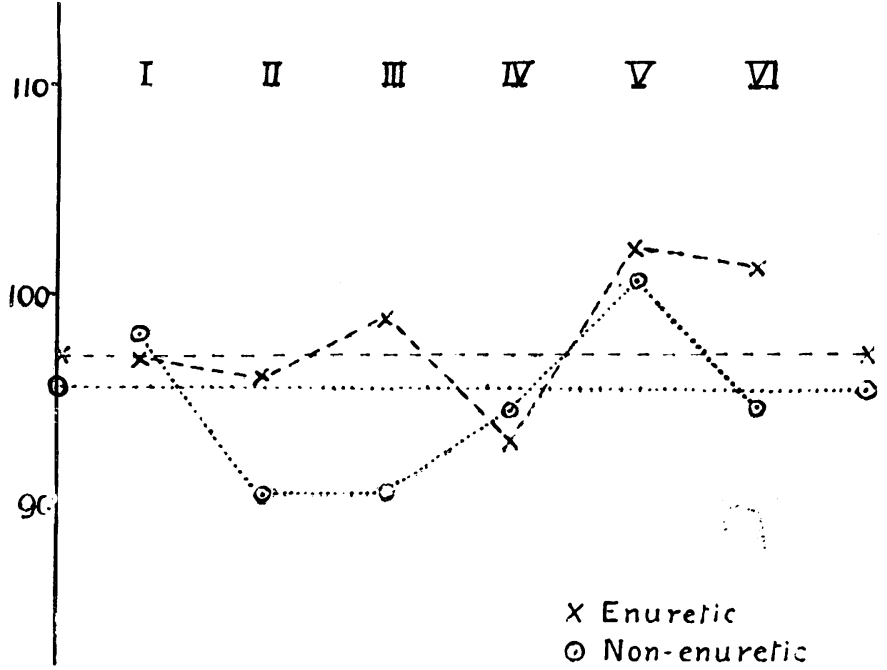

Fig. 3.

TABLE 1.

\begin{tabular}{|c|c|c|c|c|}
\hline \multirow{2}{*}{ I.Q. } & \multicolumn{2}{|r|}{ E. } & \multicolumn{2}{|r|}{ Non-E. } \\
\hline & Mean. & Standard deviation. & Mein. & Standard deviation. \\
\hline Clinic & $96 \cdot 8$ & $16 \cdot 3$ & $98 \cdot 1$ & $20 \cdot 7$ \\
\hline II. & $96 \cdot 0$ & $12 \cdot 8$ & $90 \cdot 4$ & $18 \cdot 4$ \\
\hline III. & $98 \cdot 8$ & $16 \cdot 2$ & $90 \cdot 5$ & $20 \cdot 1$ \\
\hline IV. & $94 \cdot 9$ & $15 \cdot 7$ & $94 \cdot 5$ & $17 \cdot 5$ \\
\hline V. & $102 \cdot 9$ & $19 \cdot 7$ & $100 \cdot 8$ & $20 \cdot 5$ \\
\hline VI. & $101 \cdot 7$ & $15 \cdot 8$ & $94 \cdot 6$ & $14 \cdot 1$ \\
\hline Total & $97 \cdot 0$ & $16 \cdot 5$ & $95 \cdot 5$ & $19 \cdot 6$ \\
\hline
\end{tabular}

2. Combined clinics, - It seems justified to combine the clinics for the purpose of comparing the I.Qs. It is then found that the enuretics have a higher mean I.Q. $(97 \cdot 0)$ than the non-enuretics $(95 \cdot 5)$ but this difference is hardly big enough to have any significance. See table 1 .

3. Variation.-(The variation of the individual I.Qs. about the average value is measured by the standard deviation.) In all the clinics, except clinic VI (with only 18 enuretics) the standard deviation for the non-enuretics is greater than for the enuretics. This characteristic is shown in the standard deviation of the combined clinics:-

$$
\begin{array}{ll}
\text { Standard deviation for } 982 \text { non-enuretics } & =19.6 \\
\text { Standard deviation for } 225 \text { enuretics } & =16.5
\end{array}
$$

Therefore the variation in I.Q. among the non-enuretics is significantly greater. This is due to the fact that they have a higher proportion of high I.Qs. and low I.Qs. but particularly the latter, considering the I.Qs. below 75 in more detail the following summarizes the findings :-

$$
\begin{array}{ll}
\text { Enuretics } & =21 \text { out of } 225=9.3 \text { per cent. } \\
\text { Non-enuretics } & =135,,, 982=13.7 \text { per cent. }
\end{array}
$$


Diagram comparing I.Qs. of 225 enuretics with 982 non-enuretics = All cases with I.Q's. between 60 and 130 .

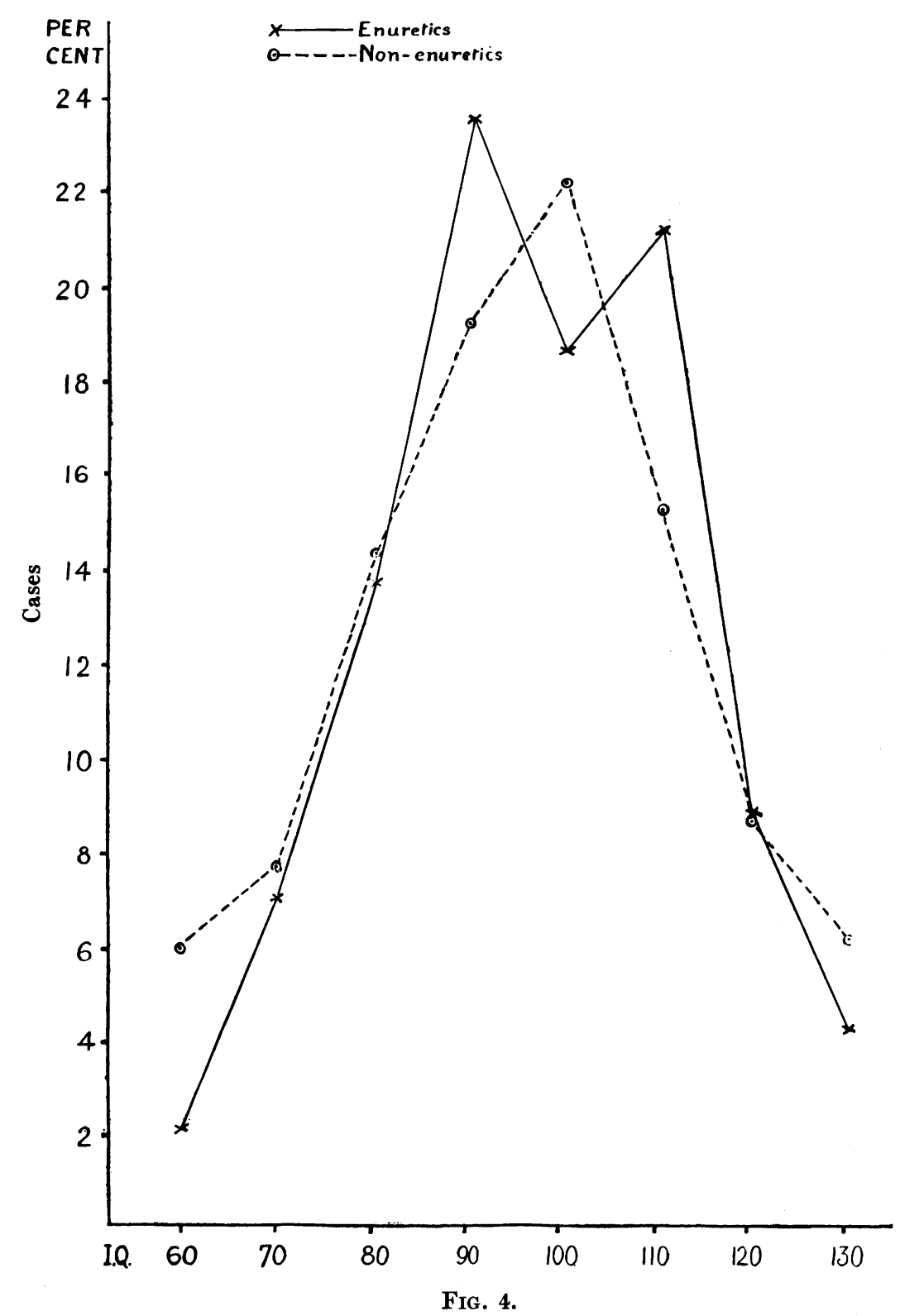

This difference is probably just significant. (N.B.-Although the clinics do not treat mental defectives some are sent for diagnosis and there are cases in which the defect has not been recognized as such but is accompanied by disorders for which treatment is asked. Thus indirectly cases are referred for mental defect and would be added to the list of non-enuretics if not 
accompanied by bed-wetting). It is interesting to note that enuresis is not an invariable symptom where the I.Q. is low, e.g. at the idiot level:-

$\begin{array}{lllcc} & & & \text { I.Q. } 40 & \text { I.Q. } 50 \\ \text { Non-enuretics } & \ldots & \ldots & 10 & 22 \\ \text { Enuretics } \ldots & \ldots & \ldots & 1 & 1\end{array}$

4. Grouping.-I.Qs. have been grouped to the nearest ten (e.g. I.Qs. 95-104 are classed as I.Q. 100) and the six clinics combined to compare the enuretics with the non-enuretics. The number of cases in each I.Q. group was then taken as a percentage of the total cases to enable the groups to be drawn together (see fig. 4). Non-enuretics show the expected peak at I.Q. 100, but the enuretics have two peaks-at I.Q. 90 and I.Q. 110. Thus on the line of I.Q. 100 there is found a difference of 3.5 per cent. between the enuretics and the non-enuretics which is doubtfully significant with such a small number of the former. But the suggestion that there are two main groups of enuretics the one tending to dull and the other to superior intelligence may fit in with clinical pictures.

5. Conclusion._-There is no striking difference in I.Q. either between clinics or between enuretics and non-enuretics when the clinics are combined. The slightly higher I.Q. for the enuretics is probably due to the higher proportion of defectives among the non-enuretics, which is not surprising considering that some of these had come to the clinic for reasons associated with mental defect.

Age.

Children are taken at the clinics from a few months old to about eighteen years. In order to get large enough groups for comparison the clinics have been combined and the ages to the nearest year (e.g. one year and seven morths to two years and six months, are classed as two years old) divided into broad groups correlated with school stages. (Since the actual ages are not given in this table and the groups are of different breadths, mean ages could not be calculated and compared. The number of enuretics in each year group would have been too small for statistical purposes.)

TABLE 2.

TOtal For all Clinics.

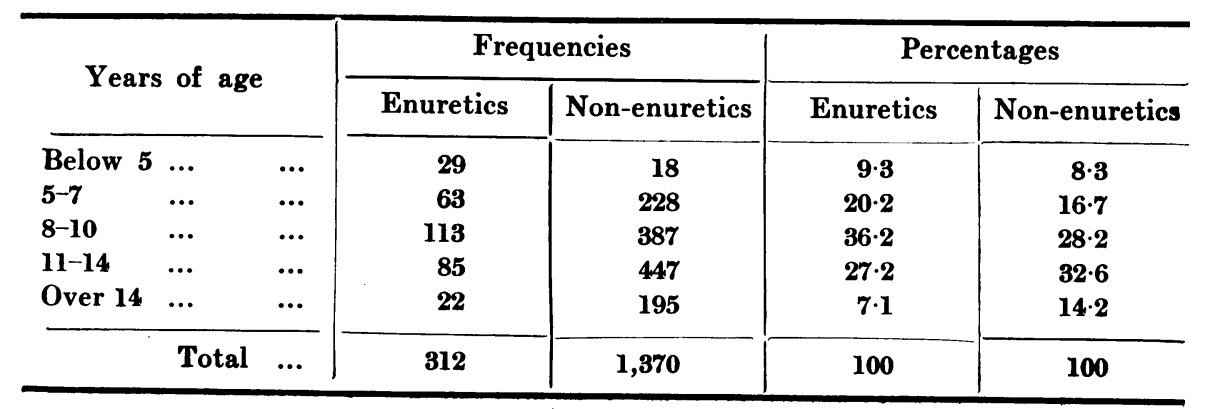


It will be seen from these figures that for ages less than eleven years there are proportionally more enuretics than non-enuretics; for ages of eleven years and over the reverse is the case. Of the enuretics 65.7 per cent. come to the clinic while in the younger age group. This contrasts with the nonenuretics of whom only $\mathbf{5 3 . 2}$ per cent. are referred at under eleven years. The difference is large enough to be important. Enuretics are in fact significantly younger than the non-enuretics-which might support the popular belief that a child 'grows out of' the symptom.

\section{Place in the family.}

1. Average size in family.-The following table gives the suggestion that enuretics come from families on the average about a third of a child larger than the non-enuretics.

$$
\begin{array}{rr}
\text { Average size of family for enuretics } & =3 \cdot 61 \\
\text { Average size of family for non-enuretics } & =3 \cdot 27 \\
\text { Difference } & 0 \cdot 34
\end{array}
$$

Having regarded the variation about the average of observations, it can be said that the difference is just on the borderline of being significant.

2. Position in family as a percentage of total cases.-The children from families of different sizes may be combined and considered only in relation to their position in family. The following table gives the number of children

\begin{tabular}{|c|c|c|c|c|c|c|}
\hline \multirow{2}{*}{\multicolumn{3}{|c|}{ Position in family }} & \multicolumn{2}{|c|}{ Frequencies } & \multicolumn{2}{|c|}{ Percentages } \\
\hline & & & Enuretics & Non-enuretics & Enuretics & Non-enuretics \\
\hline \multirow{9}{*}{\multicolumn{2}{|c|}{$\begin{array}{l}\text { lst } \\
\text { 2nd } \\
\text { 3rd } \\
\text { 4th } \\
\text { 5th } \\
\text { 6th and } \\
\text { 7th } \\
\text { 8th and 9th } \\
\text {-14th } \ldots \\
\end{array}$}} & ... & 116 & 588 & $41 \cdot 6$ & $47 \cdot 8$ \\
\hline & & ... & 72 & 283 & $25 \cdot 8$ & $22 \cdot 0$ \\
\hline & & $\ldots$ & 42 & 160 & $15 \cdot 1$ & $13 \cdot 0$ \\
\hline & & $\ldots$ & 25 & 85 & 9.0 & 6.9 \\
\hline & & ... & 12 & 40 & $4 \cdot 3$ & $\mathbf{3 \cdot 3}$ \\
\hline & & $\cdots$ & 6 & 50 & $2 \cdot 1$ & $4 \cdot 1$ \\
\hline & & ... & 6 & 23 & $2 \cdot 1$ & $1 \cdot 9$ \\
\hline & & $\cdots$ & & & & \\
\hline & Tot & ... & 279 & 1,229 & 100 & 100 \\
\hline
\end{tabular}
in each place and the percentage of the total number of cases.

TABLE 3.

These percentages do not show any marked difference between the enuretics and non-enuretics. It is not safe to draw conclusions from the marked preponderance of both groups in the position of first in the family, since ' first in a family of one child' and ' first in a family of many children', ought not to be classed together. The smaller the family the more likely it is that the child will be first and the only child is first for certain. 
If only children are eliminated the following figures are obtained:-

\begin{tabular}{|c|c|c|c|c|c|c|c|c|}
\hline \multirow{4}{*}{$\begin{array}{l}\text { Position in } \\
\text { family }\end{array}$} & \multicolumn{4}{|c|}{ Total 671} & \multicolumn{4}{|c|}{ Total 541} \\
\hline & \multicolumn{4}{|c|}{ Families of 2 and 3} & \multicolumn{4}{|c|}{ Families of 4 and more } \\
\hline & \multicolumn{2}{|c|}{ Enuretic } & \multicolumn{2}{|c|}{ Non-enuretic } & \multicolumn{2}{|c|}{ Enuretic } & \multicolumn{2}{|c|}{ Non-enuretic } \\
\hline & Number & Per cent. & Number & Per cent. & Number & Per cent. & Number & Per cent. \\
\hline $\begin{array}{lll}\text { First } & \ldots & \ldots \\
\text { Last } & \ldots & \ldots \\
\text { Other } & \text { places }\end{array}$ & $\begin{array}{c}54 \\
44 \\
19\end{array}$ & $\begin{array}{l}46 \cdot 2 \\
37 \cdot 6 \\
16 \cdot 2 \\
\end{array}$ & $\begin{array}{r}276 \\
204 \\
74\end{array}$ & $\begin{array}{l}49 \cdot 8 \\
36 \cdot 8 \\
13 \cdot 4\end{array}$ & $\begin{array}{l}18 \\
19 \\
81\end{array}$ & $\begin{array}{l}15 \cdot 3 \\
16 \cdot 2 \\
68 \cdot 5\end{array}$ & $\begin{array}{r}60 \\
84 \\
279\end{array}$ & $\begin{array}{l}14 \cdot 2 \\
19 \cdot 8 \\
66 \cdot 0\end{array}$ \\
\hline Total $\ldots$ & 117 & 100 & 554 & 100 & 118 & 100 & 423 & 100 \\
\hline
\end{tabular}

These figures do not suggest any consistent factor relative to place in family as thus compared.

3. Average position in families of different sizes. - Figure 5 shows that in families of two, three and four, both enuretics and non-enuretics are close to the line drawn to show the average position were children coming to the clinic equally likely to be anywhere in the family. In families of five and over there is an increasing tendency for the position to be below the middle, i.e., later in the family than would be expected on a purely chance hypothesis. It cannot be concluded, however, that abnormal children in large families tend to be the later children, because conditions cause the material to be selected. If large families are in contact with the clinics, it must be the younger ones that are being treated, since the older ones are above clinic age. Position in family has been taken at the time of referral and the first or second children in small families may eventually be early children in large families. Satisfactory statistical results could be obtained only from comparing completed families (see fig. 5).

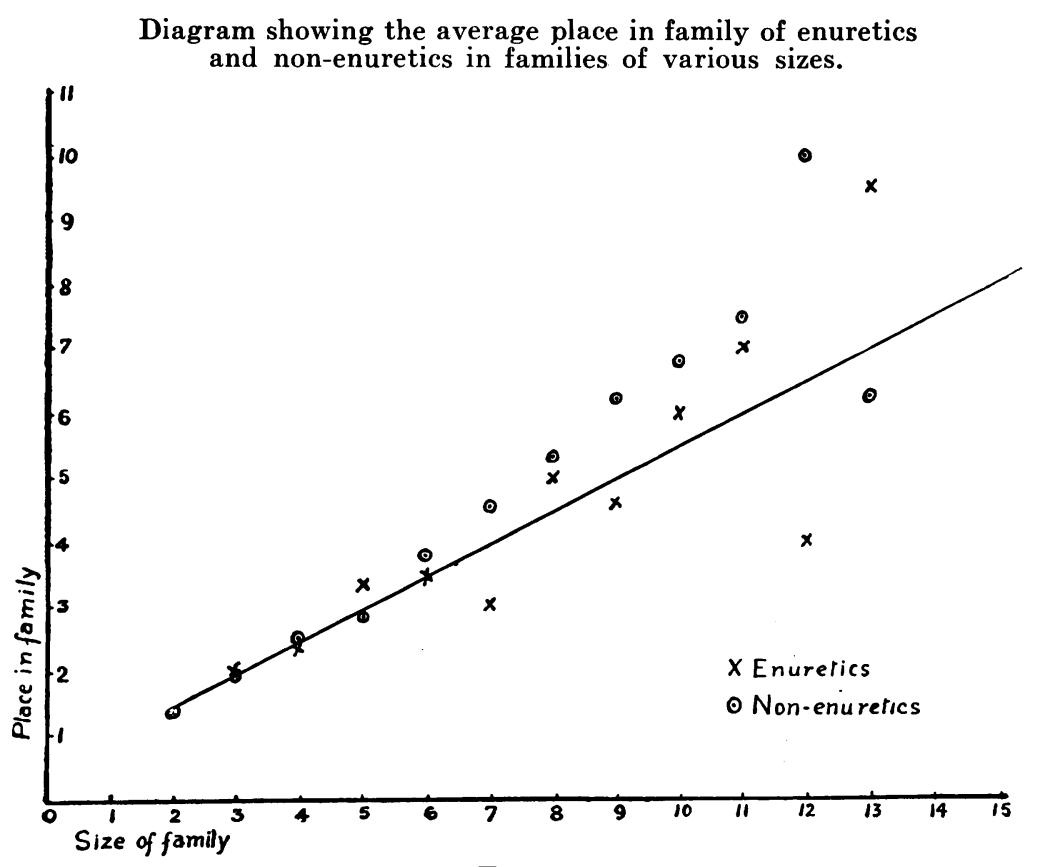

Fig. 5. 
4. Comparison of position in families of the same size.-Figure 5 shows that the position of the enuretics is always a little earlier in the family than the non-enuretics in families of sizes six to twelve. For these seven types of families we find:-

$$
\begin{array}{cccc} 
& & \text { Enuretics } & \text { Non-enuretics } \\
\text { Average position in family } & \ldots & 4 \cdot 17 & \mathbf{4} \cdot 78
\end{array}
$$

Whether this apparent difference has any meaning cannot be known from this one table (see fig. 5).

\section{Only children.-}

$\begin{array}{lccccl}\begin{array}{l}\text { Enuretics } \\ \text { Non-enuretics }\end{array} & \ldots & \ldots & \text { Frequency } & \text { Percentage } & \\ & \ldots & 259 & \underline{259} & \underline{20 \cdot 5} & \begin{array}{l}\text { of Enuretics } \\ \text { of Non-enuretics }\end{array} \\ \text { Total } & \ldots & \underline{296} & \underline{19 \cdot 6} & \text { of all cases }\end{array}$

This difference is slight, but suggests that there are if anything rather a lower proportion of enuretics among only children than in families of two or more. Even if this were accepted there is too great a variety of possible psychological interpretations about the significance of being an only child to allow of any certain deductions.

\section{Tentative deductions.}

After this presentation of the statistics on their own merits, a few of the points which have arisen may be emphasized. Almost one out of every five children referred to the clinics for whatever reason, suffers from enuresis. This prevalence and its association with different sets of symptoms (which will be dealt with in the study of selected cases) suggests that enuresis is not an entity in itself but a symptom belonging to several conditions and brought about by varying mechanisms. That the proportion of boys to girls is $3: 2$ may be related to the difference between the male and female function of bladder control, or to less easily demonstrated causes.

An important result of the comparison of I.Qs. is the evidence that the enuretics fall into two groups of high and low normal intelligence. Clinical observation has shown two main types with lack of bladder control, the slow and lethargic and the restless and anxious. Endocrine as well as psychological findings can point to this division. Each type would call for special treatment and the importance of diagnosing to which group the child belongs is obvious. Another fact which may have far-reaching implications is that the enuretics had a smaller percentage of mental defectives than the nonenuretics. This is dependent to a certain extent on clinic conditions, but the striking fact remains that there were thirty-two children with I.Qs. of 40 and 50 who were not enuretic. This shows that enuresis is by no means an invariable symptom of feeble-mindedness, not even on the idiot level. Besides suggesting that bladder control is not a function of the intelligence, necessarily deficient when intelligence is low (and therefore even idiots and 
imbeciles should be trained), this points to the constitutional and psychological factors predominating in enuresis. These findings are of much significance for treatment.

Incidence at different ages may also throw light on the nature of the symptom. Whereas non-enuretics are referred in increasing numbers for each age group up to fourteen years, the enuretics show their peak at eight to ten years and then decrease. They are significantly younger than the other cases and several reasons may be suggested. The beginning of puberty may have a specific effect as well as bringing to an end the so-called latency period when sex play is often manifest. The proximity of the genital and urinary tracts must cause congestion of one to affect the other and many indications suggest that enuresis is often connected with a sex factor. Such facts as bed-wetting occurring during periods of phantasy, as on first going to bed, and the dramatic clearing up of cases sometimes seen when tension about sex matters is relieved, point to this connection.

These considerations reach into realms beyond statistics, but speculations about quality have been based on quantitative findings. The discipline of figures was necessary to shape the path of enquiry and the tables have suggested many lines for future research.

Thanks are due to all those who facilitated the work and especially to Prof. Egon Pearson for supervising the statistics and to Miss V. E. Buxton for the patient help in checking the figures. 